\title{
HYBRID MICROWAVE WITH HEAT RECOVERY FOR AN EFFICIENT DRYING PROCESS
}

Willem P.R. Deleu ${ }^{1}$, Vincent Goovaerts ${ }^{1}$, Carlo Groffils ${ }^{1}$, ${ }^{1}$ MEAM test-center, Industrieweg 11193540 Herk-De-Stad, Belgium
willem.deleu@meam.be

Keywords: microwave, hybrid heating, heat recovery, drying

Microwave technology has come a long way from the sixties when the first microwave ovens were developed. At MEAM we have three distinct generation of microwave technology with increasing efficiency: The "first generation" of microwave ovens uses only microwaves to heat the substrate and with an efficiency of around 63\% in converting electrical energy to microwaves, this means $37 \%$ of the electric energy is lost as heat. ${ }^{1}$

The "second generation" is a hybrid oven, using both microwaves and hot air in the cavity. 2,3 This hot air is originating from the air cooled magnetrons (the $37 \%$ heat loss) and thus requires no extra energy input. The "third generation" is with added heat recovery either on the exhaust air and/or cooling water loop. The heat is used to preheat ingoing product and is especially useful if products needs to be defrosted before the microwave treatment. The possibility to use second and/or third generation microwave technology always depends on the industrial process so it is not always possible to use them. For this paper we look into drying processes at relative low temperatures $\left(<100^{\circ} \mathrm{C}\right)$ and the effect of the different generations of microwave technology on the efficiency of the process.

\section{Drying efficiency}

There are many possible ways to define/calculate the efficiency of a drying process. we define it here as the theoretical energy required to create $1 \mathrm{~kg}$ of steam of $100^{\circ} \mathrm{C}(2676$ $\mathrm{kJ} / \mathrm{kg})^{4}$ divided by the electric energy used to evaporate $1 \mathrm{~kg}$ of water in the microwave drying process (see Eq. 1). The primary reason for calculating this for a microwave drying process is to know the energy cost of drying, and to be able to compare it to other (microwave) drying processes. The second reason is to be able to see in a single process what the important parameters are and how they impact the energy consumption (= price).

$$
\begin{aligned}
\text { Drying efficiency } & =\frac{\text { theoretical energy required }}{\text { Electric energy used }} \\
\text { Drying efficiency }[\%] & =\frac{\mathrm{H}_{2} \mathrm{O} \text { evaporated }\left[\frac{\mathrm{kg}}{\mathrm{h}}\right] * 2676\left[\frac{\mathrm{kJ}}{\mathrm{kg}}\right]}{\text { Electric power }[\mathrm{kW}] * 3600\left[\frac{\mathrm{s}}{\mathrm{h}}\right]}
\end{aligned}
$$

Eq. 1 Drying efficiency formula

By using the fixed value of $2676 \mathrm{~kJ} / \mathrm{kg}$ steam produced, we underestimate the thermodynamic efficiency when process conditions are different: this value is lower when ingoing product temperature is higher than zero and/or outgoing air is colder than $100^{\circ} \mathrm{C}$. However, if the theoretical energy requirement was variable in function of the process conditions, we would not be able to correctly calculate energy cost gains/losses in function of changing process conditions. 
Choosing a fixed theoretical energy requirement thus allows us to compare efficiencies of different processes and/or microwave dyers with each other, even if ingoing and outgoing temperatures are different. This efficiency $[\mathrm{kg} \mathrm{H} 2 \mathrm{O}$ evaporated $* 2676 \mathrm{~kJ} . \mathrm{kg} / \mathrm{kJ}$ electric energy] is an interesting unit to work with industrially as it can be measured in real time by measuring the electric power consumption, the air flow and absolute water content of the ingoing and outgoing air.

If the ingoing and outgoing product moisture content, product flow and price per $\mathrm{kWh}$ electricity are known, it can also directly tell the energy price to dry a product to a certain level under current external and internal conditions. This allows calculating the impact of changes on the energy cost, and thus the process cost.

In every microwave dryer there is a need to remove the moisture from the cavity during the process. In the $1^{\text {st }}$ generation of microwave dryers, ambient air is sucked in and blown over the product while with $2^{\text {nd }}$ generation the hot air of the air cooled magnetrons is used instead. Using the hot air has a positive impact on the efficiency in several ways and we will illustrate it with process data obtained during production tests with two different machines.

Table 1. Values are the average of at least one hour of stable production data after startup period has ended. Process temperatures are infrared temperatures. Tests with $1^{\text {st }}$ and 3 th generation were performed respectively in May and February in Belgium, explaining the different inlet air temperature and relative humidity.

\begin{tabular}{|c|c|c|c|c|c|}
\hline & Inlet air & $\begin{array}{l}\text { Air to } \\
\text { cavity }\end{array}$ & $\begin{array}{c}\text { Air exiting } \\
\text { cavity }\end{array}$ & $\begin{array}{c}\text { Max } \\
\text { product } \\
\text { temperature }\end{array}$ & $\begin{array}{c}\text { Ingoing } \\
\text { product } \\
\text { temperature }\end{array}$ \\
\hline $1^{\text {st }}$ gen: & $16^{\circ} \mathrm{C}$ & $16^{\circ} \mathrm{C}$ & $23^{\circ} \mathrm{C}$ & & \\
\hline $\begin{array}{c}\text { MEAM } 32 \\
\text { M }\end{array}$ & $\begin{array}{l}60 \% \text { rel. } \\
\text { Humidity }\end{array}$ & $\begin{array}{l}60 \% \text { rel. } \\
\text { Humidity }\end{array}$ & $\begin{array}{l}67 \% \text { rel. } \\
\text { Humidity }\end{array}$ & $66^{\circ} \mathrm{C}$ & $16^{\circ} \mathrm{C}$ \\
\hline 3th gen: & $6{ }^{\circ} \mathrm{C}$ & $49^{\circ} \mathrm{C}$ & $45^{\circ} \mathrm{C}$ & & \\
\hline $\begin{array}{l}\text { MEAM dry } \\
\text { S } 48\end{array}$ & $\begin{array}{l}80 \% \text { rel. } \\
\text { Humidity }\end{array}$ & $\begin{array}{l}12 \% \text { rel. } \\
\text { Humidity }\end{array}$ & $\begin{array}{l}50 \% \text { rel. } \\
\text { Humidity }\end{array}$ & $51^{\circ} \mathrm{C}$ & $35^{\circ} \mathrm{C}$ \\
\hline
\end{tabular}

The function of the hot air in $2^{\text {nd }}$ generation microwave dryers is not transferring (a significant amount) of energy to the product like in conventional hot air dryers, but to improve following functions: lowering dew point of process air, insulating the product and heating up the launchers and cavity.

Hot air has a much higher capacity to transport vapor compared to cold air. In $1^{\text {st }}$ gen. a higher cold airflow over the product is required to keep the humidity below the dewpoint. The cold air will also be warmed up by the evaporated water and product $\left(16^{\circ} \mathrm{C}\right.$ ingoing air vs $23^{\circ} \mathrm{C}$ outgoing air see table 1) requiring energy that was first supplied to the product in the form of microwaves. By preheating the air we avoid this loss and also largely eliminate seasonal changes of air temperature and humidity that could have an significant impact on the process. The hot air also warms up the cavity and launchers, reducing the energy loss of the product due to irradiative losses.

Efficiency gains in going from $1^{\text {st }}$ to $2^{\text {nd }}$ generation is not due to additional (recuperated) energy but by reducing energy losses that occur in $1^{\text {st }}$ generation microwave dryers. 


\section{Evaporative cooling:}

While traditional hot air dryers use the airflow to heat the surface of the product, (hot) air can be used in microwave drying processes to decrease the surface temperature of the product by evaporative cooling. If the dielectric loss factor of the product is high enough, the limiting factor in the drying process is not be the speed of the energy transfer but rather the speed of mass transfer. As long as the absorbed microwave power is higher than the energy lost due to evaporation, the product will continue to heat up eventually reaching the maximum process temperature. When this maximum process temperature is low (e.g. sensitive food products), this put a serious limit to the drying speed.

We investigated the effect of evaporative cooling on the drying speed and the drying temperature for various products in the MEAM Explorer (figure 1). All samples were tested in three conditions, with no air current, with an cold air current $\left(12^{\circ} \mathrm{C}\right)$ and with an hot air current $\left(65^{\circ} \mathrm{C}\right)$ over the sample.

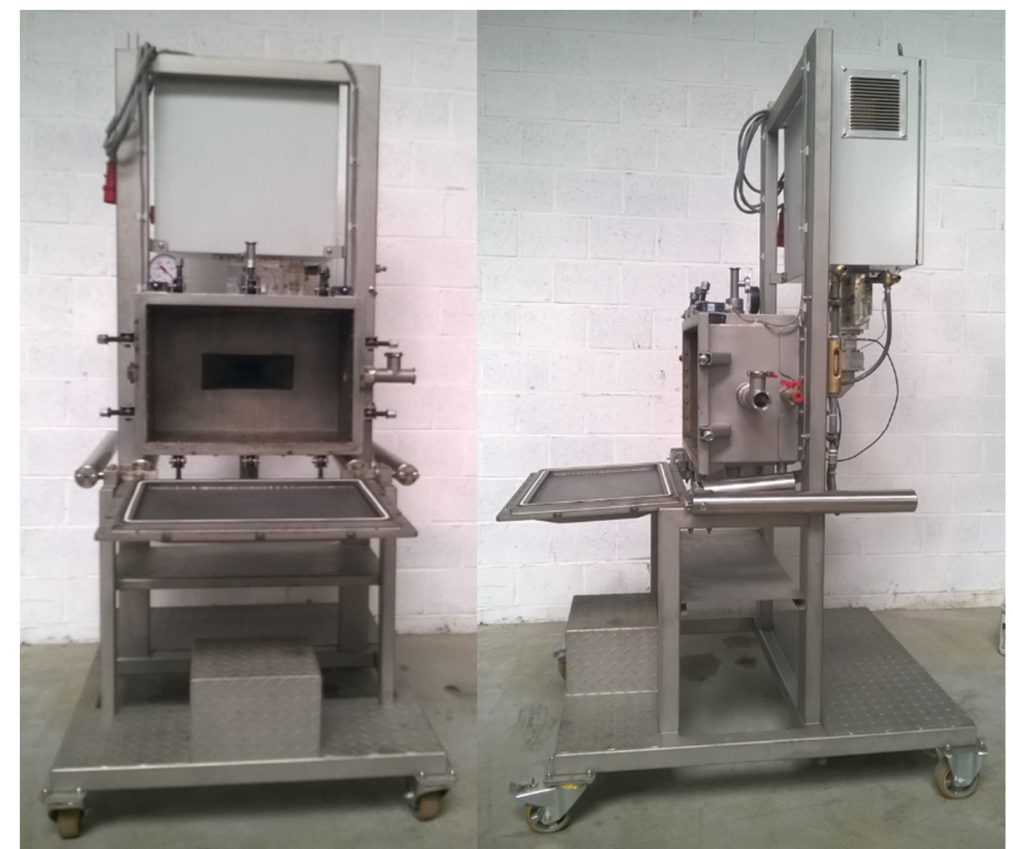

Fig. 1: MEAM Explorer: a 1.2 kW adjustable batch microwave with thermal IR camera, sample weighing and cavity openings that allow an adjustable air flow over the sample.

The first product that was dried is a granulated slag material, a by-product from metal production. This is an glassy and dense material with only water adsorbed to the surface and is thus easy to dry. Figure 1 shows three drying curves of this slag material. For this experiment, input power is regulated to keep the sample at $55^{\circ} \mathrm{C}$ while drying. Drying with a hot air current results in fast drying from $17.9 \%$ moisture to $1.69 \%$ moisture (wet weight). The input power was $1201 \mathrm{~W}$ on average. The cold air drying was slower as still $8.68 \%$ moisture (wet weight) remained after 13 min drying. Power input was $371 \mathrm{~W}$ on average. Without air current over the sample, the input power was on average $341 \mathrm{~W}$ and $12.6 \%$ moisture remained (wet weight). 


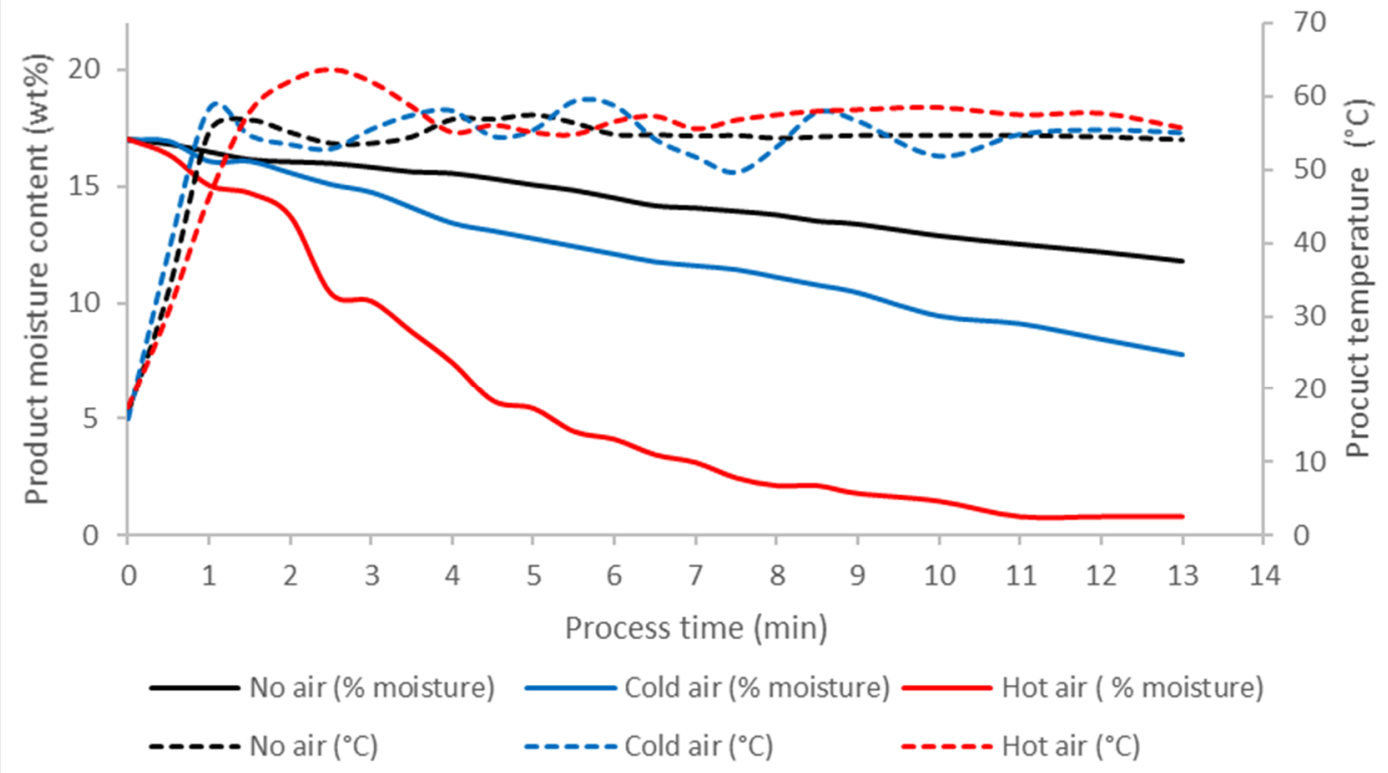

Fig. 2: Influence of air current and temperature on microwave drying curves of slag material at $55^{\circ} \mathrm{C}$.

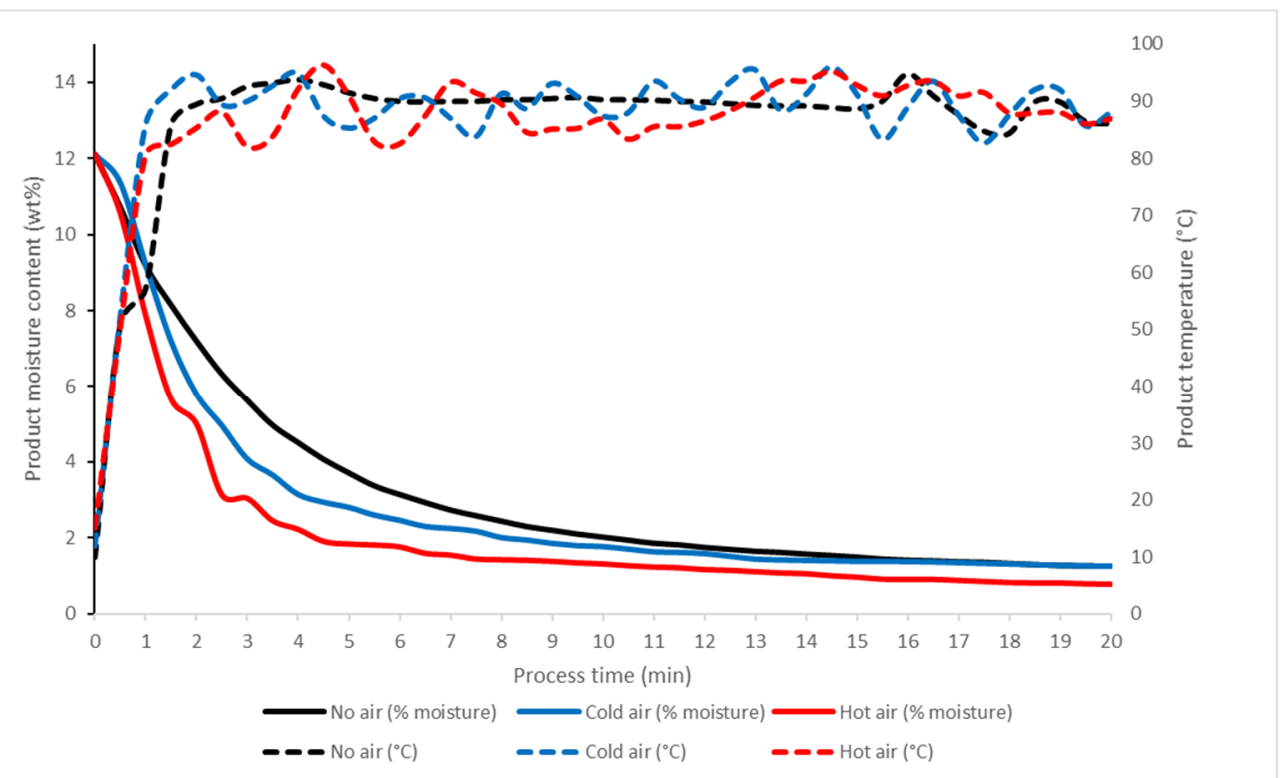

Fig. 3: Influence of air current and temperature on microwave drying curves of grass clippings at $90^{\circ} \mathrm{C}$

The second product was grass clippings that had to be dried from $12.1 \mathrm{wt} \%$ moisture to less than $1.5 \%$ moisture, the target temperature was $90{ }^{\circ} \mathrm{C}$. The test with no airflow had the slowest drying speed while the sample with an hot airflow was the fastest. Additionally, the end moisture was lower with an hot airflow. This is probably because the material is 
hygroscopic in itself, and the equilibrium between drying and moisture is shifted by using an hot airflow due to the lower partial pressure of water in hot air.

The third product was berry pomace that was dried from $40.7 \mathrm{wt} \%$ to around $10 \mathrm{wt} \%$. The drying temperature was set for $50^{\circ} \mathrm{C}$ so to prevent thermal degradation of the product.

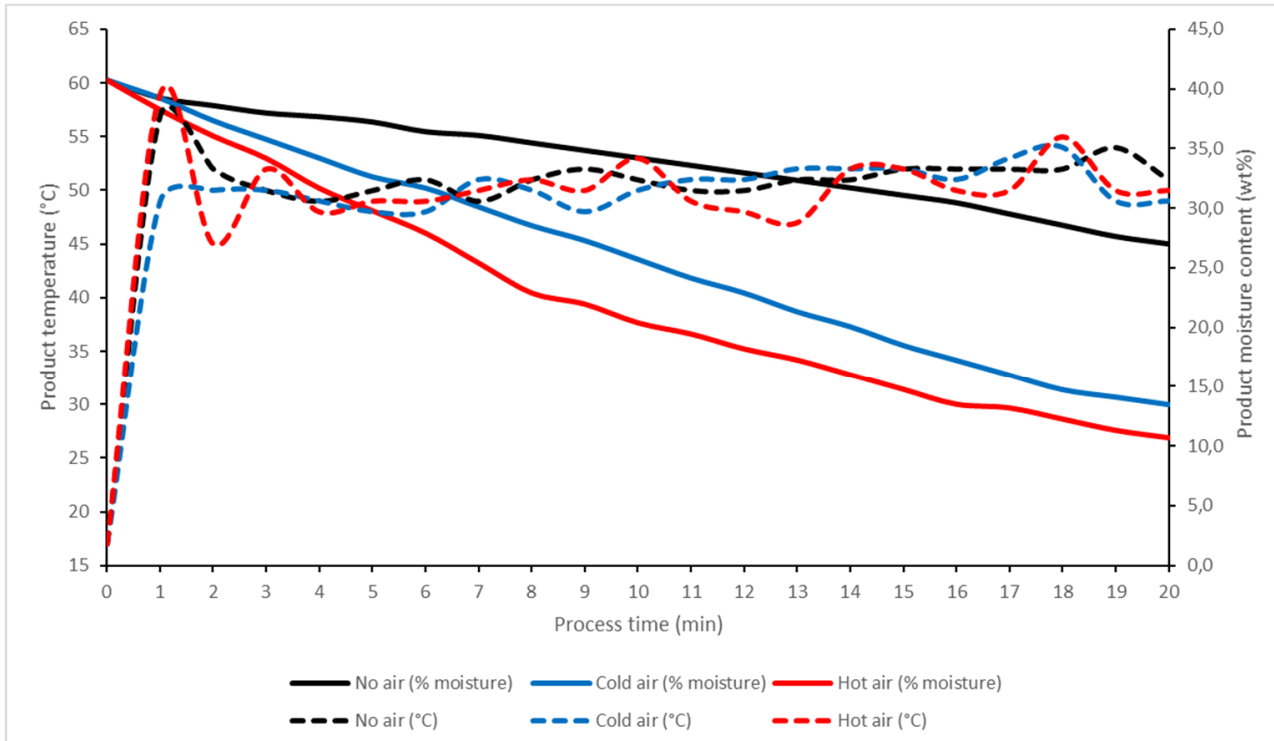

Fig. 4: Influence of air current and temperature on microwave drying curves of fruit pomace at $50{ }^{\circ} \mathrm{C}$

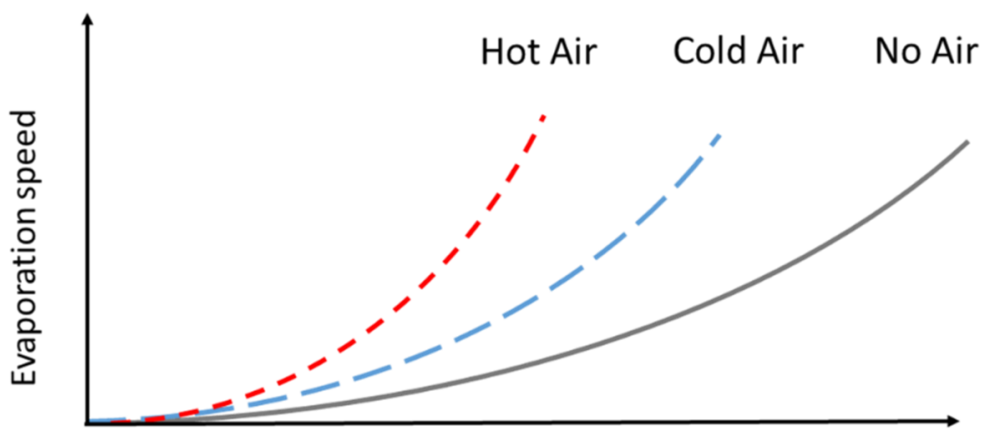

Temperature

Fig. 5: Influence of airflow on evaporation speed and temperature: At constant evaporation speed (same input MW power), the drying temperature goes down by blowing air over the

sample, with hot air being most effective. If the drying temperature is fixed, the evaporation speed can be increased by blowing air over the sample (and also increasing the input MW power). 
An air current over the sample increases evaporation rates and allows a higher input power without increasing the drying temperature or when input power is maintained, a lower drying temperature without lowering evaporation speed. The lower drying speed for the cold air samples is because hot air has a lower vapor pressure for water than cold air when both have the same absolute humidity. This will cause a faster evaporation of water in the sample with hot air and thus creates a greater evaporative cooling effect. Another way to lower vapor pressure of water is to decrease the pressure: vacuum microwave drying can operate at even lower temperatures. ${ }^{5}$

The effect of evaporative cooling is shorter process times and/or lower drying temperatures. Both are beneficial to the energy efficiency of the dryer, as shorter process times mean a smaller machine and less time to lose energy, while lower drying temperatures reduce heat loss due to a lower $\Delta \mathrm{T}$ with the environment and less energy is wasted in the form of a hot product exiting the dryer. Decreased process temperature and time have a beneficial influence on the quality of many products which is in some cases more important even than the cost of drying.

\section{Third generation: Heat recovery}

After using the waste hot air to increase evaporation rates and remove moisture from the cavity, it still contains a lot of usable energy. This energy can be used to preheat the ingoing product as long as the final temperature of the air remains above the dew point. This is why MEAM developed the "3th generation" microwave that can operate with further increased efficiency by the addition of a heat recovery unit that preheats ingoing frozen product. A stable test run of 7.30 hours was done on the MEAM dry S48 to determine the efficiency of the system. Total energy consumption of the machine at maximum capacity including electronics and fans is $68 \mathrm{~kW}$.

During the test run of $7.5 \mathrm{~h}$, on average $82 \mathrm{~kg}$ of product was dried per hour resulting in 52 $\mathrm{kg}$ of water being evaporated per hour. The drying efficiency of the machine calculated with equation 1 is $57 \%$ for the trial run. (note that this efficiency was obtained during an experimental run with an unbalanced load) The product was placed on the belt frozen at $5^{\circ} \mathrm{C}$ and after being preheating with the outgoing product air entered the cavity at $31^{\circ} \mathrm{C}$. The theoretical power needed for defrosting $\left(333 \mathrm{~kJ} / \mathrm{kg} \mathrm{H}_{2} \mathrm{O}\right)$ and heating it to $31^{\circ} \mathrm{C}(4.18$ $\mathrm{kJ} / \mathrm{kg} . \mathrm{K})$ is $8.4 \mathrm{~kW}$ with $82 \mathrm{~kg}$ ingoing product per h. This is an underestimation as the heat capacity of the dry product is not included in the calculation. When the $8.4 \mathrm{~kW}$ from heat recovery is added to the $68 \mathrm{~kW}$ total electric power of the MEAM dry S48, the total sum of ingoing power is $76.4 \mathrm{~kW}$, with heat recovery accounting for $11 \%$ of that amount.

\section{Conclusion.}

In this paper, we show three generations of microwave technology and how each successive generation has a positive influence on the efficiency of the microwave drying process. Using the hot air from air-cooled magnetrons, the $2^{\text {nd }}$ generation can cut energy losses that are inherent to the $1^{\text {st }}$ generation of microwave dryers. The hot air also increases evaporative cooling effects in the product allowing shorter process times and lower process temperatures. By using heat recovery on the wet exhaust air from the dryer, the $3^{\text {th }}$ generation microwave dryer can cut the energy cost of defrosting and preheating ingoing product accounting to more than $10 \%$ of the energy required in the process. 


\section{References}

1. Jacques Thury, Microwaves: Industrial, scientific, and medical applications, ISBN 0-89006-448-2.

2. Pieter Luypaert, (1981), Patent EP0069105 : Industrial modular microwave oven.

3. Pieter luypaert et al. (2006), Patent WO2004054324: Industrial microwave oven for the thermal treatment of products and method applied thereby in particular for killing insects in wood.

4. Ashim K. Data, Biological and bioenvironmental heat and mass transfer, ISBN 0824707753.

5. V. Goovaerts, K. Groffils, C. Groffils, $16^{\text {th }}$ International Conference on Microwave and High Frequency Heating, AMPERE 2017, Delft, The Netherlands, September 18-21, "Control of evaporation temperature in a microwave vacuum drying system”. 